American Journal of Immunology 5 (3): 98-100, 2009

ISSN 1553-619X

(C) 2009 Science Publications

\title{
Atopic Dermatitis and Type 1 Diabetes Mellitus in Iranian Children
}

\author{
${ }^{1}$ Elham Ahmadi, ${ }^{2}$ Zahra Rahnama and ${ }^{3}$ Ali Rikhtegaran Tehrani \\ ${ }^{1}$ Department of Pediatrics, Kerman Neuroscience Research Center, Kerman \\ University of Medical Sciences, Iran \\ ${ }^{2}$ Department of Dermatology, Kerman University of Medical Sciences, Iran \\ ${ }^{3}$ Department of Public Health, Kerman University of Medical Sciences, Iran
}

\begin{abstract}
Problem statement: Atopic diseases, including asthma, eczema and allergic rhinitis, are characterized by a chronic inflammatory reaction mediated by $\mathrm{T}$ helper 2 cells, while type 1 diabetes mellitus is mediated by $\mathrm{T}$ helper 1 cells. Approach: The aim of this study was to compare the prevalence of atopic dermatitis between children with type 1 diabetes mellitus and age-matched controls. We conducted a case-control study enrolling 150 cases with type 1 diabetes mellitus between 2-20 years from pediatric endocrine out patient clinic and 450 controls randomly selected from the general population matched on sex and age. The diagnosis of atopic dermatitis was determined for patients and controls by the Hanifin and Rajka's diagnostic criteria. Results: From 150 cases, 75 (50\%) were male and $75(50 \%)$ were female, with the age between 2 and 20 and among the 450 controls, 228 were male (50.66\%) and 222 were female $(49.33 \%)$ the age was as the case. Dermatitis past or present, was identified in $1.3 \%$ of cases and $3.1 \%$ of controls, a difference which was not statistically significant $(\mathrm{P}>0.05)$. Conclusion: In present study, the prevalence of atopic dermatitis was comparable in diabetic children and the controls which may be due to difference between races and geographic areas and lack of support for an inverse relationship between the Th2-mediated atopy and th1-mediated autoimmune disorder. Further studies are needed to show the difference in serum IgE and cytokine profiles between the groups.
\end{abstract}

Keywords: Atopic dermatitis, case control study, children, diabetes mellitus, Iran

\section{INTRODUCTION}

Atopic Dermatitis (AD) is an itchy, chronic or chronically relapsing, inflammatory skin condition. The age of onset is between 2 and 6 months in the majority of cases, but it may start at any age, even before the age of 2 months in some Cases. The clinical features include: itching, macular erythema, papules or papulovesicles, Eczematous areas with crusting, Lichenification and excoriation, Dryness of the skin, secondary infection ${ }^{[1]}$.

About 2/3 of patients with AD have a Th2 (The|per2) immune reactivity pattern ${ }^{[2]}$. $\mathrm{AD}$ is a common disease. The consequence of the rising prevalence of $\mathrm{AD}$ is a heavy burden on medical Services and budgets ${ }^{[3]}$ The prevalence of AD in Iran is about $2 \%{ }^{[4]}$.

Type 1 Diabetes mellitus (T1D) develops as a result of the synergistic effects of genetic, environmental and immunologic factors that ultimately destroy the pancreatic beta cells. T1D results from autoimmune beta cell destruction, which leads to insuline deficiency. Criteria for the diagnosis of DM are:

- Symptoms of diabetes plus random blood glucose concentration $\geq 11.1 \mathrm{mmol} \mathrm{L}^{-1}\left(200 \mathrm{mg} \mathrm{dL}^{-1}\right)$

- Fasting plasma glucose $\geq 7.0 \mathrm{mmol} \mathrm{L}^{-1}$ $\left(126 \mathrm{mg} \mathrm{dL}^{-1}\right.$ )

- Two hour plasma glucose $\geq 11.1 \mathrm{mmol} \mathrm{L}^{-1}$ $\left(200 \mathrm{mg} \mathrm{dL}^{-1}\right)$ during an oral glucose tolerance test $^{[5]}$

It seems that T1D has a Th1 (T-helper 1) immune reactivity pattern. There is often a reciprocal relationship between Th1 immune responses, which suggests that $\mathrm{AD}$ (Th2 phenotype) and T1D (Th1 Phenotype) are unlikely to coexist in the same individual $^{[2]}$.

Few studies have investigate the association between T1D and $\mathrm{AD}$ and the results are controversy between different studies.

Corresponding Author: Elham Ahamadi, Department of Pediatrics, Kerman Neuroscience Research Center, Somayeh Cross-In Front of Besat Clinic Kerman, P.O. Box 76175-113, Kerman, Iran 
The study carried out by Rosenbauer and collagues in Germany 2003 indicates that atopic eczema in early childhood could be protective against $\mathrm{T}_{1} \mathrm{D}^{[5]}$, however another study carried out in Netherlands by Meerwaldt and collagues ${ }^{[4]}$ shows the lower prevalence of asthma, hay fever and eczema symptoms in DM patients compared with age-matched controls, although not statistically significant, is consistent with the Th1/Th2 concept $^{[6]}$. The aim of our study is to determine the association between these two diseases, in our city, because such studies were not conducted in this region and if we can found an association, further studies are needed to determine the pathogenesis.

\section{MATERIALS AND METHODS}

We conducted a case-control study enrolling 150 cases with T1D between 2-20 years from pediatric endocrine outpatients and 450 controls randomly selected from the general population matched on sex and age. The diagnosis of $\mathrm{AD}$ was determined for patients and controls by the Hanifin and Rajka's diagnostic criteria ${ }^{[1]}$. Which is the most suitable one for determining this disease in population based studies. To compare the Frequency of categorical variables, chi square test was used and using multivariate logistic regression, the association between diabetes and $\mathrm{AD}$ was analyzed.

\section{RESULTS}

From 150 cases, 75 (50\%) were male and 75 (50\%) were female, the mean age of cases was 9.46 with a range between 2 and $20(\mathrm{SD}=3.38)$ and among the 450 controls, 228 were male $(50.66 \%)$ and 222 were female $(49.33 \%)$, with a mean of $9.55(\mathrm{SD}=3.74)($ Table 1$)$.

Dermatitis past or present, was identified in $1.3 \%$ of cases and $3.1 \%$ of controls and the difference was not statistically significant $(p>0.05)$. The relative frequency of dermatitis was $3.7 \%$ among women and $1.7 \%$ among men $(\mathrm{p}>0.05)$.

Table 1: The association between type 1 diabetes mellitus and AD by multivariate logistic regression

\begin{tabular}{|c|c|c|c|c|c|c|}
\hline \multirow[b]{2}{*}{ Variable } & \multirow[b]{2}{*}{ Total } & \multicolumn{2}{|c|}{ Dermatitis } & \multirow{2}{*}{$\begin{array}{l}\text { Adjusted } \\
\text { odds } \\
\text { ratio }\end{array}$} & \multirow{2}{*}{$\begin{array}{l}\text { Confidence } \\
\text { interval } \\
95 \%\end{array}$} & \multirow[b]{2}{*}{ p-value } \\
\hline & & Yes & No & & & \\
\hline$\overline{\text { Age }}$ & 600 & $8.4 \pm 4.6$ & $9.6 \pm 3.6$ & 0.91 & $0.80-1.04$ & 0.177 \\
\hline \multicolumn{7}{|l|}{ Gender } \\
\hline Female & 297 & $11(3.7)$ & $286(96.3)$ & - & $0.14-1.28$ & 1.129 \\
\hline $\begin{array}{l}\text { Male } \\
\text { Diabbetes }\end{array}$ & 303 & $5(1.1)$ & $298(98.3)$ & 0.43 & & \\
\hline Yes & 150 & $2(1.3)$ & $148(98.1)$ & - & $0.10-2.1$ & 0.336 \\
\hline No & 450 & $14(3.1)$ & $436(96.9)$ & 0.47 & & \\
\hline
\end{tabular}

\section{DISCUSSION}

Atopic patients are Known to have hyper-reactivity of the Th2 immune mechanism ${ }^{[7]}$. Immune disregulation is an important factor in the creation of this condition ${ }^{[8]}$.

"Th1 and Th2 cells have been found to be mutually antagonistic leading to either Th1 or Th2 dominated responses upon immunization, ${ }^{,[9]}$.

Another study carried out by Simpson et al. ${ }^{[10]}$ shows that Th1 and Th2 mediated diseases are significantly associated in a large general practice population. This finding support the proposal that autoimmune and atopic diseases share risk factors that increase the propensity of the immune system to generate both Th1 and Th2 mediated inappropriate responses to non-pathological antigens ${ }^{[11,12]}$.

\section{CONCLUSION}

In our study, the incidence of dermatitis among patients with T1D was 1.3 and $3.1 \%$ in control group, but it was not statistically significant ( $p>0.05$ ), may be due to difference between races and geographic areas and lack of support for an inverse relationship between Th2 mediated atopy and Th1-mediated autoimmune disorders.

More studies are needed to show the differences in serum $\operatorname{IgE}$ and cytokine profiles among patients.

\section{REFERENCES}

1. Olesen, A.B., S. Juul, N. Birkebaek and K. Thestrup-Pedersen, 2001. Association between atopic dermatitis and insuline-dependent diabetes mellitus: A case-control study. Lancet, 357: 1749-1752.

http://www.ncbi.nlm.nih.gov/pubmed/ 11403811

2. Cardwrell, C.R., M.D. Shields, D.J. Carson and C.C. Patterson, 2003. A Meta analysis of the association between childhood type1 diabetes mellitus and atopic disease. Diabet. Care, 26: 2568-2574.

http://www.ncbi.nlm.nih.gov/pubmed/ 12941720

3. Williams, H.C., 2005. Clinical practice. Atopic dermatitis. N. Engl. J. Med., 352: 2314-2324. http://www.ncbi.nlm.nih.gov/pubmed/ 15930422

4. Meerwaldt, R., R.Y. Odink and R. Landaeta et al., 2003. A lower prevalence of atopy symptoms in children with type 1 diabetes mellitus. Clin. Exp. Allergy., $\quad 32$ : 254-255. http://www.ncbi.nlm.nih.gov/pubmed/11929490 
5. Rottem, M., M. Szyper-Kravitz and Y. Shoenfeld, 2005. Atopy and asthma in migrants. Int. Arch. Allergy Immunol., 136: 198-204. http://www.ncbi.nlm.nih.gov/pubmed/15711097

6. Rosenbauer, J. and H. Gianig, 2003. Atopic eczema in early childhood could be protective against type1 diabetes. Diabetologia, 46: 784-780. http://www.ncbi.nlm.nih.gov/pubmed/ 12802494

7. Horwitz, A.A., J. Hossain and E. Yousef, 2009. Correlates of outcome for atopic dermatitis. Ann. Allergy. Asthma. Immunol., 103: 146-451. http://www.ncbi.nlm.nih.gov/pubmed/19739428

8. EURODIAB Substudy 2 Study Group, 2000. Decreased prevalence of atopic diseases in children with diabetes. J. Pediatr., 137: 446-449. http://www.ncbi.nlm.nih.gov/pubmed/11035823

9. Laffaille J.J., 1998. The role of helper $\mathrm{T}$ cell subsets in autoimmune diseases. Cytokine. Growth Factor Rev., 9: 139-151. http://www.ncbi.nlm.nih.gov/pubmed/9754708
10. Simpson, C.R., W.J.A. Anderson, P.J. Helms M.W. Taylor and L. Watson et al., 2002. Coincidence of immune-mediated diseases driven by Th1 and Th2 subsets suggests a common aetiology. A population-based study using computerized general practice data. Clin. Exp. Allergy, 32: 37-42. http://www.ncbi.nlm.nih.gov/pubmed/12002734

11. Bieber, T., and N. Novak, 2009. Pathogenesis of atopic dermatitis: new developments. Curr. Allergy Asthma Rep., 9: 291-294. http://www.ncbi.nlm.nih.gov/pubmed/19656476

12. Sheikh, A., L. Smeeth, and R. Hubbard, 2003. There is no evidence of an inverse relationship between TH2-mediated atopy and TH1-mediated auto immune disorders: Lack of support for the hygiene hypothesis. J. Allergy Clin. Immunol., 111: 131-135.

http://www.ncbi.nlm.nih.gov/pubmed/8123195 